International Journal of Gastroenterology and Hepatology Research

\title{
Serrated gastric Adenocarcinoma Developed on a Hyperplastic Polyp Gastric Adenocarcinoma Developed on Scalloped Polyp
}

${ }^{l}$ Departement of gastroenterology. Habib Thameur Hospital, Tunisia

${ }^{2}$ Departement of pathology. Habib Thameur Hospital, Tunisia

${ }^{3}$ Departement of surgery. Habib Thameur Hospital, Tunisia

Corresponding Author: Sabbah Meriam, Habib Thameur Hospital, 8 Rue El Messelekh, Montfleury, 1008,

Tunis, Tunisia

Received date: July 20, 2019; Accepted date: July 26, 2019; Published date: July 29, 2019.

DOI: https://doi.org/10.31546/IJGHR.1001

A 69 years old woman with no past medical facts, presented vomiting, gastric pain and loss of weight. Abdominal examination was normal. Upper endoscopy showed a circumferential antral tumor (figure 1). ACE and CA19,9 levels were normal. CT scan objectified a stenosing antral tumor associated with perigastric lymph nodes with no hepatic or pulmonary metastases (figure 2). She underwent subtotal gastrectomy with lymphadenectomy and Finesterer gastrojejunal anastomosis. Histologically, there was a Carcinomatous component showing glands with marked serrated neoplastic epithelium resulting in a sawtooth like architechture (figure 3). It was developed on hyperplastic polyp (figure 4). Tumor was classified T3N0 M0 according to TNM classification. She received post operative chemotherapy (FOLFOX).

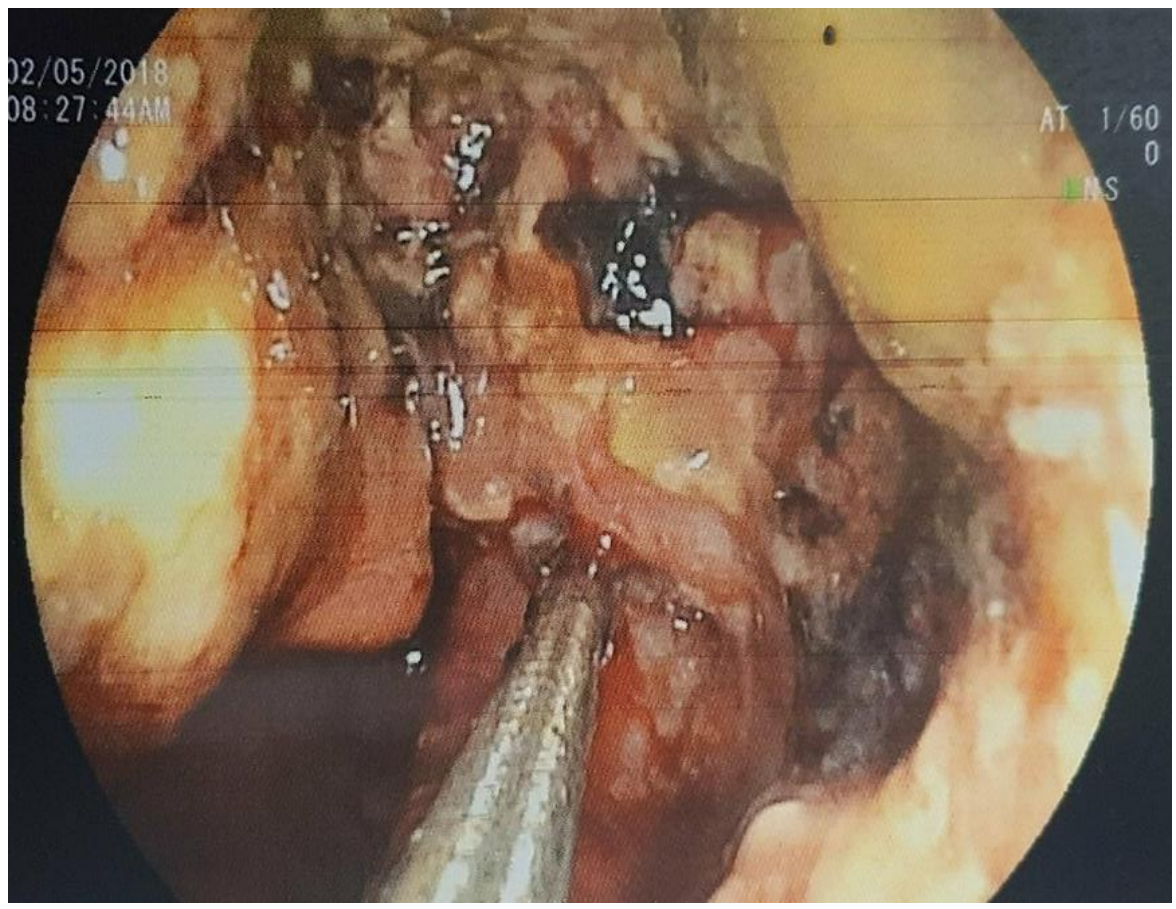

Figure 1: Upper endoscopy showed a circumferential antral tumor 


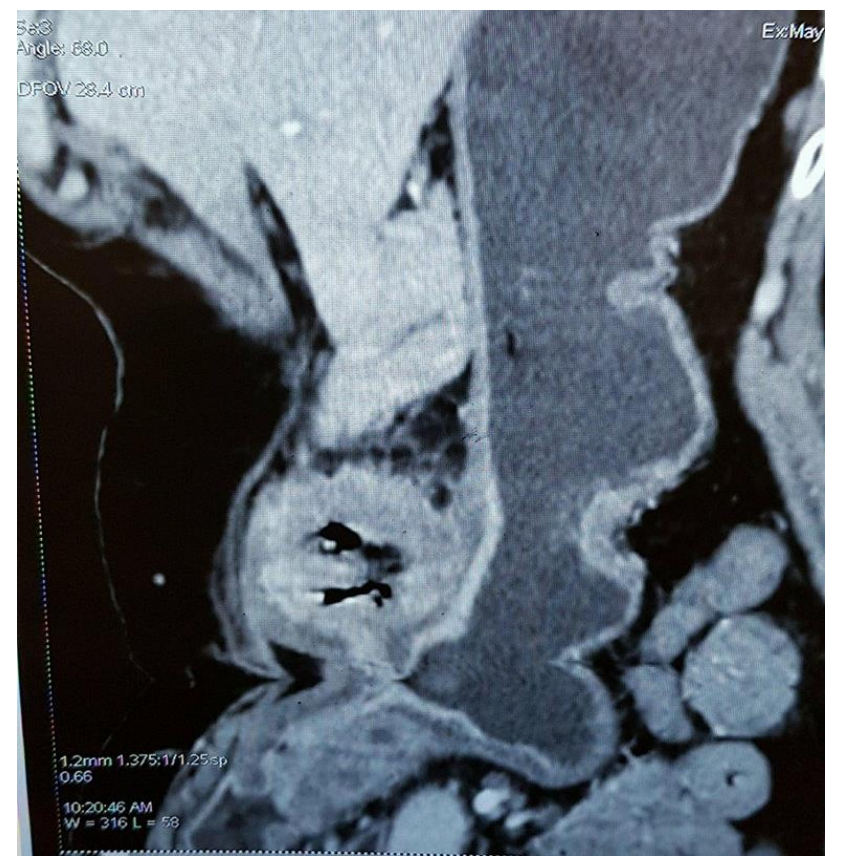

Figure 2: CT scan : stenosing antral tumor associated with perigastric lymph nodes with no hepatic or pulmonary smetastases.
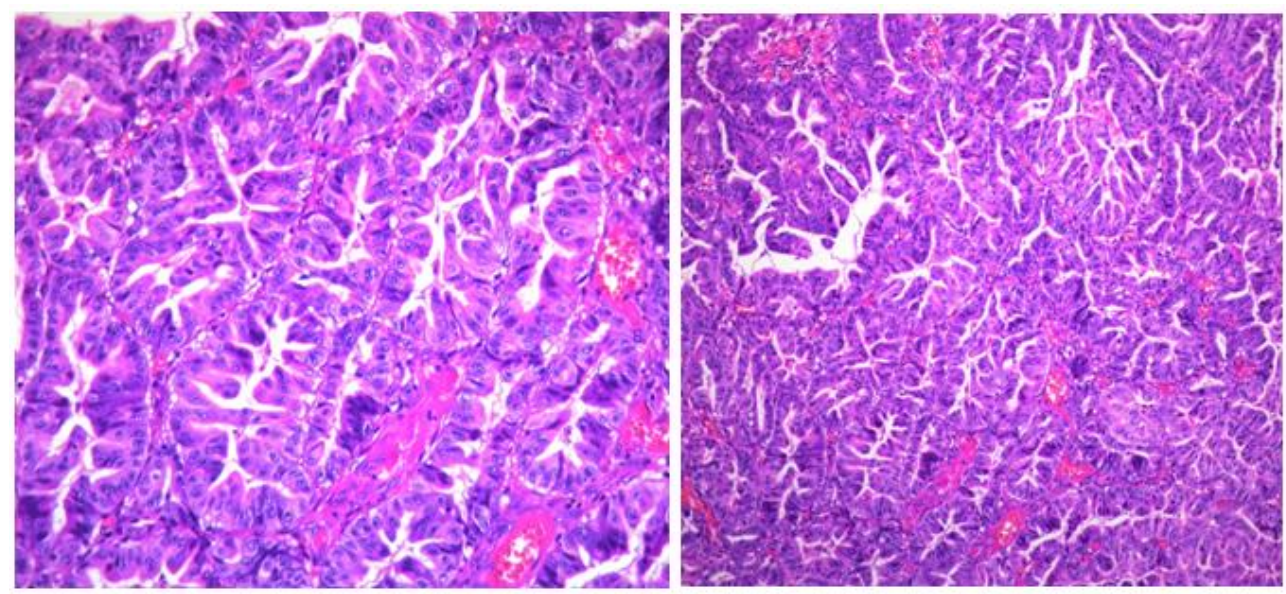

Figure 3 : Carcinomatous component showing glands with marked serrated neoplastic epithelium resulting in a saw tooth like architecture.
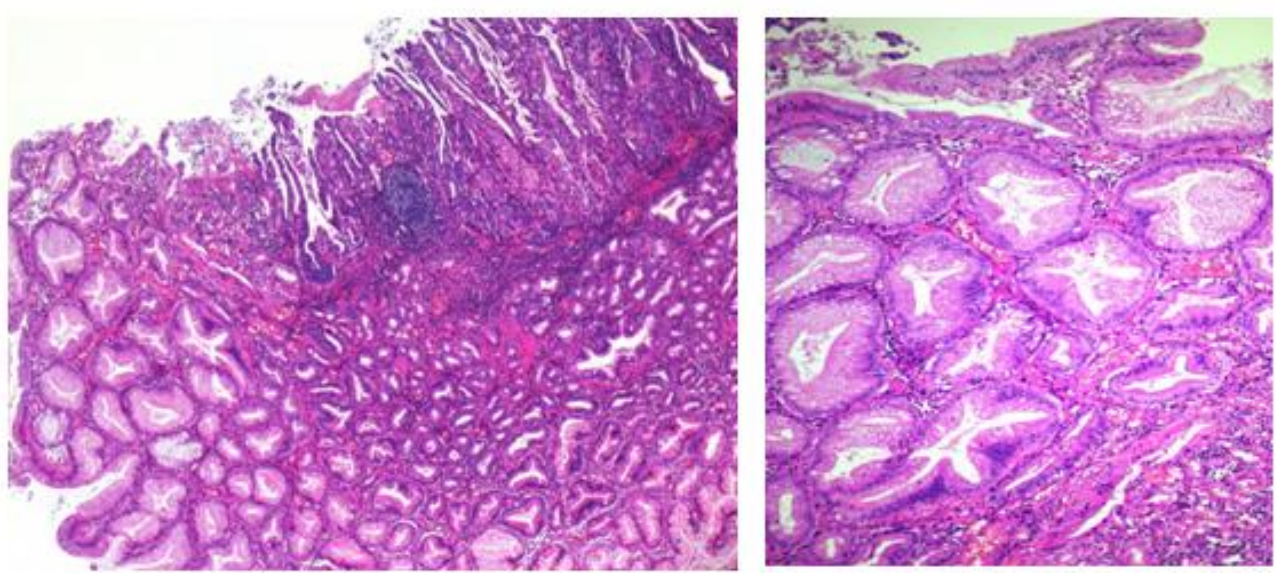

Figure 4: Low power view of reminescent area of hyperplastic polyp (Area of hyperplastic polyp: hyperplastic foveoli with serrated identations) to the left in continuity with a serrated invasive adenocarcinoma to the right . 